\title{
Utility of glycated albumin for the diagnosis of diabetes mellitus in a Japanese population study: results from the Kyushu and Okinawa Population Study (KOPS)
}

\author{
N. Furusyo $\cdot$ T. Koga $\cdot$ M. Ai $\cdot$ S. Otokozawa $\cdot$ \\ T. Kohzuma • H. Ikezaki • E. J. Schaefer • J. Hayashi
}

Received: 10 March 2011 / Accepted: 24 August 2011 /Published online: 27 September 2011

(C) Springer-Verlag 2011

\begin{abstract}
Aims/hypothesis Glycated albumin is a measure of the mean plasma glucose concentration over approximately 2 3 weeks. We determined reference values for glycated albumin, and assessed its utility for the diagnosis of type 2 diabetes mellitus in the general population.

Methods We studied 1,575 men and women (mean age, 49.9 years; range, 26-78 years) who participated in a periodic health examination in a suburban Japanese town. $\mathrm{HbA}_{1 \mathrm{c}}$ and fasting plasma concentrations of glucose (FPG) and glycated albumin were measured. Participants with FPG $\geq 7.0 \mathrm{mmol} / 1$ or $\mathrm{HbA}_{1 \mathrm{c}} \geq 6.5 \%(48 \mathrm{mmol} / \mathrm{mol})$ were
\end{abstract}

N. Furusyo $(\bowtie) \cdot$ J. Hayashi

Department of General Internal Medicine,

Kyushu University Hospital,

3-1-1, Maidashi, Higashi-Ku,

Fukuoka 812-8582, Japan

e-mail: furusyo@gim.med.kyushu-u.ac.jp

N. Furusyo $\cdot$ T. Koga $\cdot$ H. Ikezaki $\cdot$ J. Hayashi

Department of Environmental Medicine and Infectious Diseases,

Kyushu University,

Fukuoka, Japan

M. Ai $\cdot$ S. Otokozawa $\cdot$ E. J. Schaefer

Lipid Metabolism Laboratory,

Tufts University School of Medicine,

Boston, MA, USA

M. Ai

Life Science and Bioethics Research Center,

Tokyo Medical and Dental University,

Tokyo, Japan

T. Kohzuma

Diagnostics Department, Asahi Kasei Pharma Corporation,

Tokyo, Japan diagnosed as having diabetes. In our laboratory, the glycated albumin assay had intra-assay and inter-assay CVs of $1.1 \%$ and $1.6 \%$, respectively.

Results Glycated albumin levels were significantly correlated with $\mathrm{HbA}_{1 \mathrm{c}}$ levels $(r=0.766, p<0.001)$ and FPG $(r=$ $0.706, p<0.001)$. The presence of diabetes was significantly higher in participants with glycated albumin levels between $15.0 \%$ and $15.9 \%$ (five of $276,1.81 \%$ ) than in those with glycated albumin $<14 \%$ (three of $672,0.45 \%)(p=0.037$ ), and was markedly increased in those with a glycated albumin level $>16 \%$ (58 of 207, 28.0\%). Receiver operating characteristic curve analysis indicated that a glycated albumin level of $\geq 15.5 \%$ was optimal for predicting diabetes, with a sensitivity of $83.3 \%$ and a specificity of $83.3 \%$.

Conclusions/interpretation There is merit to further investigating the potential for glycated albumin to be used as an alternative measure of dysglycaemia for future research and clinical practice.

Keywords Diabetes · Epidemiology · Glycated albumin . $\mathrm{HbA}_{1 \mathrm{c}}$

$\begin{array}{ll}\text { Abbreviations } \\ \text { ARIC } & \text { Atherosclerosis Risk in Communities } \\ \text { FPG } & \text { Fasting plasma glucose } \\ \text { HOMA-IR } & \text { HOMA of insulin resistance } \\ \text { JDS } & \text { Japanese Diabetes Society } \\ \text { JSCC } & \text { Japanese Society for Clinical Chemistry } \\ \text { KOPS } & \text { Kyushu and Okinawa Population Study } \\ \text { NGSP } & \begin{array}{l}\text { National Glycohemoglobin Standardization } \\ \end{array} \\ \text { Program } \\ \text { ROC } & \text { Receiver operating characteristic }\end{array}$




\section{Introduction}

Type 2 diabetes mellitus has become a worldwide health problem especially in developed countries. Long-term hyperglycaemia is a major risk factor for cardiovascular disease, as are nephropathy, neuropathy and retinopathy, which all worsen the quality of life of patients with diabetes [1]. It is imperative to diagnose diabetes at an early stage and to keep blood glucose concentrations within the normal range [2]. According to the Diabetes Epidemiology: Collaborative Analysis of Diagnostic Criteria in Europe (DECODE) [3], the Funagata study [4], and the Study to Prevent-NIDDM [5], individuals with large glucose fluctuations are more likely to develop macrovascular disease, including cardiovascular disease, even at early stages of glucose intolerance. Screening and intervention for diabetes in the earliest stages are advocated for the prevention of diabetic complications and cardiovascular disease.

$\mathrm{HbA}_{1 \mathrm{c}}$ is the standard for monitoring mean plasma glucose concentrations over $2-3$ months, and has been used in many clinical studies such as the Diabetes Control and Complications Trial [2], United Kingdom Prospective Diabetes Study [6], and Kumamoto studies [7], providing evidence that patients with poor glycaemic control develop diabetic nephropathy, neuropathy and retinopathy, and indicating that intensive therapies for lowering plasma glucose concentrations can reduce the risk for these diabetic complications. The joint 2009 guidelines from the ADA [8] and the new WHO guidelines [9] propose the measurement of $\mathrm{HbA}_{1 \mathrm{c}}$ as a diagnostic criterion for diabetes, suggesting a cut-off of $\geq 6.5 \%$ ( $48 \mathrm{mmol} / \mathrm{mol})$ as being diagnostic.

Glycated albumin reflects mean glycaemia over approximately 2-3 weeks. Compared with $\mathrm{HbA}_{1 \mathrm{c}}$, glycated albumin is characterised by more rapid and greater changes, and can be used to confirm treatment effects when initiating or changing medications. Glycated albumin can also be used for patients with anaemia or haemoglobinopathies for whom measured $\mathrm{HbA}_{1 \mathrm{c}}$ levels may be inaccurate [10-17]. Recently, a user-friendly, highly accurate, automated enzymatic assay for measuring glycated albumin has been developed [14] and approved for clinical use in Japan. Studies using self-monitoring of blood glucose and continuous glucose monitoring have found glycated albumin levels to better reflect glycaemic fluctuation [15, 16]. Moreover glycated albumin levels were better correlated with severity of cardiovascular disease, and were also found to be a better indicator of glycaemic fluctuations than $\mathrm{HbA}_{1 \mathrm{c}}$ [17].

Although many previous studies have shown the utility of glycated albumin, they were often based on a relatively small number of participants $(n<1,000)$ and have provided very limited data on the utility of glycated albumin for the screening and diagnosis of diabetes. Moreover, despite its clinical approval in Japan, there are only limited normal range data for glycated albumin. Our goals were to provide reference range values for glycated albumin and to evaluate its utility as a screening and diagnostic tool for diabetes in a large Japanese community-based population study. In this cross-sectional study, we tested the hypothesis that glycated albumin can be a useful tool for diagnosing diabetes in the general population as part of a medical evaluation.

\section{Methods}

Study population The current study began in 2007 as a survey of the incidence of macrovascular events associated with lifestyle-related diseases among the general population as a part of the Kyushu and Okinawa Population Study (KOPS) [18]. In this substudy we evaluated residents of Kasuya Town, a suburban area with about 35,500 residents and adjacent to Fukuoka City, the largest city on Kyushu Island. The participants were residents notified by local newspaper and public announcements of a free annual health examination given by our department. Of 1,836 residents (544 men, 1,292 women, age range 22-96 years) who underwent a health check at the Kasuya Health and Welfare centre between May and September 2007, 33 who were 80 years of age or over, 37 with incomplete data and 62 who did not agree to enrolment (response rate 99.9\%) were excluded, leaving 1,704 residents to participate in the study. Of the 1,704 participants who reported for the examination, 129 were excluded because they were being treated for diabetes, anaemia, thyroid disease, liver disease or nephropathy, leaving 1,575 participants available for analysis (469 men and 1,106 women, mean age: 49.9 years, age range 26-78 years). Nephropathy was defined as an estimated GFR of $\leq 60 \mathrm{ml} \mathrm{min}^{-1} 1.73 \mathrm{~m}^{-2}$ or the presence of macro-albuminuria. Positive results for urinary protein were identified using the dipstick test (Ames dipstick, Bayer Medical, Tokyo, Japan) for spot urine. Subjects were considered positive for macro-albuminuria when the dipstick result was positive, corresponding to a urinary protein level of over $300 \mathrm{mg} / \mathrm{l}$. Recently, it was reported that stage II diabetic nephropathy with micro-albuminuria, but not macro-albuminuria, did not affect the glycated albumin level [19]. These participants underwent medical evaluations in 2007, at which time they were interviewed about their personal medical history (including menopause), family medical history and lifestyle-related habits, as described elsewhere [18]. About $75 \%$ of the women aged $\geq 50$ years (438 of 579) reported entering menopause. Common laboratory tests were included in the examination as outlined below. To ensure the validity of the data, all doctors carrying out the study were staff members of the General Internal Medicine Department of Kyushu Univer- 
sity, and were trained with regard to the study protocol and the medical procedures necessary for the study. The present study was approved by the Kyushu University Hospital Ethics Committee, and written informed consent was obtained from all participants prior to the examination. This study was carried out in accordance with the principles of the Declaration of Helsinki as revised in 2000.

Anthropometry and body fat distribution Anthropometric measurements were performed with each participant wearing indoor clothing and without shoes. BMI was calculated as weight $(\mathrm{kg})$ divided by height $(\mathrm{m})$ squared. Waist circumference was measured at a level midway between the lowest rib and the iliac crest in a standing position. Hip circumference was measured by putting a tape around the widest part of the hip area over minimal clothing and in a standing position. WHR was the ratio of the circumference of the waist to that of the hip. Systolic BP and diastolic BP were measured on the right arm in the sitting position with an automated sphygmomanometer (HEM-780, Omron Healthcare, Kyoto, Japan) after a 5 min rest.

Laboratory measurements All blood samples were collected $8 \mathrm{~h}$ after an overnight fast. Aliquots of whole blood, and fresh serum and plasma samples from each participant were immediately separated and sent at $4{ }^{\circ} \mathrm{C}$ to a clinical laboratory testing company (SRL, Fukuoka, Japan) for the measurement of fasting plasma glucose (FPG), fasting serum insulin and $\mathrm{HbA}_{1 \mathrm{c}}$.

FPG concentrations were measured using a hexokinaseglucose-6-phosphate dehydrogenase method (Quick Auto Neo GLU-HK, Sinotest, Tokyo, Japan). Fasting serum insulin concentration was measured by a chemiluminescent enzyme immunoassay (Lumipulse Presto Insulin, Fujirebio, Tokyo, Japan). HOMA of insulin resistance (HOMA-IR) was calculated using the following formula: fasting serum insulin $(\mathrm{pmol} / \mathrm{l}) \times \mathrm{FPG}(\mathrm{mmol} / \mathrm{l}) / 156[20]$.

$\mathrm{HbA}_{1 \mathrm{c}}$ levels were measured from fresh whole blood samples with an immune coherent method (RAPIDIA Auto $\mathrm{HbA}_{1 \mathrm{c}}$; Fujirebio). The levels were originally calculated using the method of the Japanese Diabetes Society (JDS) and Japanese Society for Clinical Chemistry (JSCC) and then converted to US National Glycohemoglobin Standardization Program (NGSP) format. The $\mathrm{HbA}_{1 \mathrm{c}}$ levels that we report are expressed as NGSP levels (\%) [21] and International Federation of Clinical Chemistry and Laboratory Medicine (IFCC) units ( $\mathrm{mmol} / \mathrm{mol})$.

All remaining serum and plasma samples were immediately frozen and stored at $-80^{\circ} \mathrm{C}$ until assayed. Aliquots of serum and plasma samples from each participant were sent on dry ice to the Lipid Metabolism Laboratory at Tufts University (Boston, MA, USA) for an international collaboration comparing markers of lipid metabolism and glucose homeostasis in Japanese and US populations. In the laboratory, the assays listed below were run by the first four authors (NF, TK, MA and SO) on a Hitachi 911 Analyzer (Hitachi, Tokyo, Japan).

Plasma glycated albumin levels were measured with a Lucica GA-L kit (Asahi Kasei Pharma, Tokyo, Japan). This assay uses a glycated amino acid elimination reaction for an improved enzymatic glycated albumin measurement assay, which has correlated very highly $(r=0.99)$ with values for glycated albumin obtained by HPLC assay [14]. The assay is stable even for samples stored for a long period of time (frozen for 19-23 years) [22]. Although the actual CVs for the automated assay had no international reference standard or reference method, the assay had intra-assay and interassay CVs of $1.1 \%$ and $1.6 \%$, respectively, in laboratories at both Tufts University and Asahi Kasei Pharma.

Plasma total cholesterol (Determiner L TC II, Kyowa Medex, Tokyo, Japan) and triacylglycerol (Determiner L TG II, Kyowa Medex) concentrations were measured using automated standardised enzymatic analysis. Plasma HDLcholesterol was measured using a direct homogenous assay of the plasma using detergents (Determiner L HDL-C, Kyowa Medex). The Lipid Metabolism Laboratory maintains lipid standardisation with the Centers for Disease Control, Atlanta, Georgia, for these assays, and intra-assay and inter-assay CVs were less than $2 \%[13,22]$.

Definition of newly acquired diabetes For participants with no history of diabetes or treatment for diabetes, a new diagnosis of diabetes mellitus was made if FPG was $\geq 7.0 \mathrm{mmol} / 1 \mathrm{and} /$ or $\mathrm{HbA}_{1 \mathrm{c}}$ was $\geq 6.5 \%(48 \mathrm{mmol} / \mathrm{mol})$.

Statistical analysis All statistical analyses were performed using StatFlex (Artec, Osaka, Japan). Data are reported as means $\pm \mathrm{SD}$, median, first quartile, third quartile, IQR or percentage within each category. Spearman correlation coefficient analysis was carried out using the entire population. Student's $t$ test and the Mann-Whitney $U$ test were used to compare between-group differences, while the KruskalWallis test was used for multiple group comparisons. The cut-off value of glycated albumin for newly diagnosed diabetes was calculated by receiver operating characteristic (ROC) analysis. A $p$ value of $<0.05$ was considered statistically significant, except for the Kruskal-Wallis tests, where a $p$ value of $<0.01$ was considered significant.

\section{Results}

The influence of sex, age and BMI on glycated albumin and $H b A_{l c}$ Data on the men and women studied are shown in Table 1. In this population the mean BMI was $23.7 \mathrm{~kg} / \mathrm{m}^{2}$ in 
Table 1 Characteristics of 1,575 participants from the general population of Fukuoka Prefecture, Japan, classified by sex

Data are shown as mean \pm SD unless stated otherwise

${ }^{a}$ Data are shown as median (first quartile, third quartile) because of the skewed distributions

HOMA-IR was calculated using the following formula: fasting serum insulin $(\mathrm{pmol} / \mathrm{l}) \times \mathrm{FPG}$ $(\mathrm{mmol} / \mathrm{l}) / 156$

* $p$ value for the comparison of men and women

\begin{tabular}{|c|c|c|c|}
\hline Variable & Men $(n=469)$ & Women $(n=1106)$ & $p$ value* \\
\hline Age (years) & $51.0 \pm 9.5$ & $49.4 \pm 9.8$ & 0.002 \\
\hline BMI $\left(\mathrm{kg} / \mathrm{m}^{2}\right)$ & $23.7 \pm 3.2$ & $21.6 \pm 3.0$ & $<0.001$ \\
\hline WHR $(\%)$ & $88.5 \pm 5.8$ & $84.3 \pm 7.0$ & $<0.001$ \\
\hline Systolic BP (mmHg) & $127.8 \pm 18.3$ & $119.7 \pm 20.4$ & $<0.001$ \\
\hline Diastolic BP (mmHg) & $76.2 \pm 13.3$ & $69.0 \pm 12.2$ & $<0.001$ \\
\hline FPG $(\mathrm{mmol} / \mathrm{l})$ & $5.53 \pm 1.85$ & $4.94 \pm 0.75$ & $<0.001$ \\
\hline Serum albumin $(\mathrm{g} / \mathrm{l})$ & $46.4 \pm 2.40$ & $45.6 \pm 2.20$ & $<0.001$ \\
\hline Glycated albumin (\%) & $14.39 \pm 3.15$ & $14.43 \pm 1.77$ & 0.723 \\
\hline $\mathrm{HbA}_{1 \mathrm{c}}(\%)$ & $5.54 \pm 0.91$ & $5.38 \pm 0.49$ & \multirow[t]{2}{*}{$<0.001$} \\
\hline $\mathrm{HbA}_{1 \mathrm{c}}(\mathrm{mmol} / \mathrm{mol})$ & $37.0 \pm 10.0$ & $35.3 \pm 5.3$ & \\
\hline Fasting serum insulin $(\mathrm{pmol} / 1)^{\mathrm{a}}$ & $32.6(21.5,50.7)$ & $29.9(20.8,47.9)$ & 0.344 \\
\hline HOMA-IR ${ }^{\mathrm{a}}$ & $1.11(0.68,1.76)$ & $0.93(0.63,1.53)$ & 0.069 \\
\hline Total cholesterol $(\mathrm{mmol} / \mathrm{l})$ & $5.47 \pm 0.95$ & $5.49 \pm 0.93$ & 0.751 \\
\hline HDL-cholesterol (mmol/l) & $1.47 \pm 0.35$ & $1.72 \pm 0.38$ & $<0.001$ \\
\hline Triacylglycerol $(\mathrm{mmol} / \mathrm{l})^{\mathrm{a}}$ & $1.32(0.95,1.92)$ & $0.87(0.64,1.18)$ & $<0.001$ \\
\hline
\end{tabular}

men and $21.6 \mathrm{~kg} / \mathrm{m}^{2}$ in women. Only $2.3 \%$ of the participants had a low plasma concentration of HDLcholesterol ( $<1.0 \mathrm{mmol} / 1$ in men and $<1.3 \mathrm{mmol} / \mathrm{l}$ in women) and $17.8 \%$ of the entire population had hypertriacylglycerolaemia (fasting plasma triacylglycerol $>1.7 \mathrm{mmol} / \mathrm{l}$ ). No participants had a serum albumin concentration $<35 \mathrm{~g} / 1$.

While no significant sex differences were observed for glycated albumin, fasting serum insulin concentration or HOMA-IR, mean $\mathrm{HbA}_{1 \mathrm{c}}$ level and FPG were significantly higher in men than in women (Table 1). The mean glycated albumin level rose significantly with age, with levels at 30 39 years of $13.7 \%$, at $40-49$ years of $14.0 \%$, at $50-59$ years of $14.8 \%$ and at $60-69$ years of $14.8 \%(p<0.001)$. The mean $\mathrm{HbA}_{1 \mathrm{c}}$ level also rose significantly with age, with levels at $30-39$ years of $5.2 \%(33 \mathrm{mmol} / \mathrm{mol})$, at $40-49$ years of $5.3 \%$ (34 $\mathrm{mmol} / \mathrm{mol})$, at $50-59$ years of $5.6 \%(38 \mathrm{mmol} / \mathrm{mol})$ and at $60-69$ years of $5.5 \%(37 \mathrm{mmol} / \mathrm{mol})(p<0.001)$. While no significant differences were found between the glycated albumin levels in participants with $\mathrm{BMI} \geq 25 \mathrm{~kg} / \mathrm{m}^{2}(14.3 \pm$ $2.3 \%)$ and those with BMI $<25 \mathrm{~kg} / \mathrm{m}^{2}(14.4 \pm 2.0 \%$; $p=$ $0.351)$, the $\mathrm{HbA}_{1 \mathrm{c}}$ level and FPG were significantly $(p<$ $0.001)$ higher in participants with $\mathrm{BMI} \geq 25 \mathrm{~kg} / \mathrm{m}^{2}(5.7 \pm 0.6 \%$ $[39 \pm 7 \mathrm{mmol} / \mathrm{mol}]$ and $5.58 \pm 1.29 \mathrm{mmol} / \mathrm{l})$ than in those with BMI $<25 \mathrm{~kg} / \mathrm{m}^{2}(5.4 \pm 0.5 \%$ [36 $\pm 6 \mathrm{mmol} / \mathrm{mol}]$ and $5.02 \pm$ $1.02 \mathrm{mmol} / \mathrm{l})$.

Information on the differences between premenopausal and postmenopausal women is provided in Table 2 . Postmenopausal women had significantly higher FPG, $\mathrm{HbA}_{1 \mathrm{c}}$ and glycated albumin levels than premenopausal women. Postmenopausal women also had significantly higher mean values for BMI, WHR, systolic and diastolic BP, and plasma concentrations of total cholesterol and triacylglycerol than premenopausal women.
In Table 3, we present selected percentile concentrations for glycated albumin, FPG, $\mathrm{HbA}_{1 \mathrm{c}}$ and fasting serum insulin. For glycated albumin, 75th percentile values were approximately $15.0 \%$, while 90 th percentile values were approximately $16.5 \%$ for both men and women. In this population the approximate 90th percentile values for $\mathrm{FPG}, \mathrm{HbA}_{1 \mathrm{c}}$ and insulin were: $6.0 \mathrm{mmol} / 1,6.0 \%(42 \mathrm{mmol} / \mathrm{mol})$ and $60 \mathrm{pmol} / \mathrm{l}$, respectively.

Correlations among glycated albumin, FPG, and $H b A_{1 c}$ Figure 1 shows the correlations between glycated albumin and FPG (Fig. 1a), HbA $1 \mathrm{c}$ and FPG (Fig. 1b), and glycated albumin and $\mathrm{HbA}_{1 \mathrm{c}}$ (Fig. 1c). FPG concentrations had significant positive correlations to $\mathrm{HbA}_{1 \mathrm{c}}$ level $(r=0.836$, $p<0.001)$ and glycated albumin level $(r=0.706, p<0.001)$. The positive correlation coefficient between $\mathrm{HbA}_{1 \mathrm{c}}$ and glycated albumin was $0.766(p<0.001)$. FPG concentrations of $5.56,6.11$ and $7.00 \mathrm{mmol} / 1$ corresponded to $\mathrm{HbA}_{1 \mathrm{c}}$ and glycated albumin levels of $5.6 \%(38 \mathrm{mmol} /$ $\mathrm{mol}), 5.9 \%$ (41 $\mathrm{mmol} / \mathrm{mol})$ and $6.3 \%(45 \mathrm{mmol} / \mathrm{mol})$, and $15.0 \%, 15.7 \%$ and $16.9 \%$, respectively. The ratio of glycated albumin:HbA $1 \mathrm{c}$ (NGSP) was 2.68.

Newly diagnosed diabetes Diabetes was newly diagnosed in 72 participants $(4.6 \%$ of total). Of the 72,16 had abnormal FPG $(\geq 7.0 \mathrm{mmol} / \mathrm{l})$ only, 36 had both abnormal FPG and $\mathrm{HbA}_{1 \mathrm{c}}(\geq 6.5 \%$ [48 $\left.\mathrm{mmol} / \mathrm{mol}]\right)$ and $20 \mathrm{had}$ abnormal $\mathrm{HbA}_{1 \mathrm{c}}$ only. The respective median levels (IQR) of FPG, $\mathrm{HbA}_{1 \mathrm{c}}$ and plasma glycated albumin were 7.47 (2.75) mmol/1, $6.80(1.46) \%$ (49.4 [14.8] mmol/mol) and $18.2(6.13) \%$ for participants with diabetes, while they were $4.88(0.61) \mathrm{mmol} / \mathrm{l}, 5.30(0.40) \%$ (34.1 [4.08] $\mathrm{mmol} / \mathrm{mol})$ and $14.1(1.91) \%$ for those without diabetes. The preva- 
Table 2 Characteristics of 1,106 women participants from the general population of Fukuoka Prefecture, Japan, classified by menopausal status

Data are shown as mean $\pm \mathrm{SD}$ unless stated otherwise

${ }^{\mathrm{a}}$ Data are shown as median (first quartile, third quartile) because of the skewed distributions

HOMA-IR was calculated using the following formula: fasting serum insulin $(\mathrm{pmol} / \mathrm{l}) \times \mathrm{FPG}$ $(\mathrm{mmol} / \mathrm{l}) / 156$

* $p$ value for the comparison of premenopausal and postmenopausal women

\begin{tabular}{|c|c|c|c|}
\hline Variable & Premenopausal $(n=668)$ & Postmenopausal $(n=438)$ & $p$ value* \\
\hline Age (years) & $42.8 \pm 6.6$ & $59.4 \pm 2.7$ & $<0.001$ \\
\hline BMI $\left(\mathrm{kg} / \mathrm{m}^{2}\right)$ & $21.3 \pm 3.0$ & $22.1 \pm 2.9$ & $<0.001$ \\
\hline WHR (\%) & $82.7 \pm 6.6$ & $86.8 \pm 6.8$ & $<0.001$ \\
\hline Systolic BP (mmHg) & $113.8 \pm 17.1$ & $128.5 \pm 21.8$ & $<0.001$ \\
\hline Diastolic BP (mmHg) & $66.8 \pm 11.7$ & $72.4 \pm 12.2$ & $<0.001$ \\
\hline FPG (mmol/l) & $4.85 \pm 0.83$ & $5.07 \pm 0.60$ & $<0.001$ \\
\hline Serum albumin $(\mathrm{g} / \mathrm{l})$ & $45.5 \pm 2.20$ & $45.7 \pm 2.00$ & 0.089 \\
\hline Glycated albumin (\%) & $14.15 \pm 1.77$ & $14.86 \pm 1.69$ & $<0.001$ \\
\hline $\begin{array}{l}\mathrm{HbA}_{1 \mathrm{c}}(\%) \\
\mathrm{HbA}_{1 \mathrm{c}}(\mathrm{mmol} / \mathrm{mol})\end{array}$ & $\begin{array}{l}5.29 \pm 0.52 \\
34.3 \pm 5.6\end{array}$ & $\begin{array}{l}5.51 \pm 0.41 \\
36.7 \pm 4.5\end{array}$ & $<0.001$ \\
\hline Fasting serum insulin $(\mathrm{pmol} / \mathrm{l})^{\mathrm{a}}$ & $29.2(20.1,46.5)$ & $31.9(22.9,49.3)$ & 0.218 \\
\hline HOMA-IR ${ }^{\mathrm{a}}$ & $0.88(0.58,1.43)$ & $1.01(0.73,1.58)$ & 0.530 \\
\hline Total cholesterol (mmol/l) & $5.24 \pm 0.88$ & $5.87 \pm 0.88$ & $<0.001$ \\
\hline HDL-cholesterol (mmol/l) & $1.70 \pm 0.37$ & $1.70 \pm 0.39$ & 0.138 \\
\hline Triacylglycerol $(\mathrm{mmol} / \mathrm{l})^{\mathrm{a}}$ & $0.78(0.59,1.08)$ & $1.01(0.76,1.39)$ & $<0.001$ \\
\hline
\end{tabular}

lences of newly diagnosed diabetes by glycated albumin range (glycated albumin $<14.0 \%, 14.0-14.9 \%, 15.0$ $15.9 \%, \quad 16.0-16.9 \%, 17.0-17.9 \%, 18.0-18.9 \%, 19.0-$
$19.9 \%$ and $\geq 20.0 \%$ ) were $0.45 \%, 1.43 \%, 1.81 \%, 3.81 \%$, $28.0 \%, 47.1 \%, 75.0 \%$ and $96.3 \%$, respectively (Fig. 2). According to ROC analysis, the cut-off level for glycated
Table 3 Means and selected percentiles of glycated albumin level, fasting plasma glucose concentration, $\mathrm{HbA}_{1 \mathrm{c}}$ level and fasting serum insulin concentration in participants from the general population of Fukuoka Prefecture, Japan, according to sex and the menopausal status of women
The numbers of men, women, premenopausal women and postmenopausal women tested were 469, 1,106, 668 and 438, respectively

\begin{tabular}{|c|c|c|c|c|c|c|}
\hline \multirow[t]{2}{*}{ Variable } & \multirow[t]{2}{*}{ Mean (SD) } & \multicolumn{5}{|c|}{ Percentile } \\
\hline & & 10th & 25 th & 50 th & 75 th & 90th \\
\hline \multicolumn{7}{|l|}{ Glycated albumin (\%) } \\
\hline Men & $14.39(3.15)$ & 11.8 & 12.8 & 13.8 & 15.0 & 16.8 \\
\hline Women & $14.43(1.77)$ & 12.6 & 13.4 & 14.3 & 15.3 & 16.2 \\
\hline Premenopausal women & $14.15(1.77)$ & 12.0 & 13.2 & 14.1 & 14.9 & 15.7 \\
\hline Postmenopausal women & $14.86(1.69)$ & 13.0 & 13.8 & 14.7 & 15.7 & 16.6 \\
\hline \multicolumn{7}{|l|}{ FPG $(\mathrm{mmol} / \mathrm{l})$} \\
\hline Men & $5.53(1.85)$ & 4.56 & 4.82 & 5.11 & 5.56 & 6.50 \\
\hline Women & $4.94(0.75)$ & 4.39 & 4.56 & 4.83 & 5.11 & 5.39 \\
\hline Premenopausal women & $4.85(0.83)$ & 4.28 & 4.50 & 4.78 & 5.03 & 5.33 \\
\hline Postmenopausal women & $5.07(0.60)$ & 4.50 & 4.72 & 5.00 & 5.28 & 5.39 \\
\hline \multicolumn{7}{|l|}{$\mathrm{HbA}_{1 \mathrm{c}}(\%)$} \\
\hline Men & $5.54(0.91)$ & 5.0 & 5.1 & 5.3 & 5.6 & 6.3 \\
\hline Women & $5.38(0.49)$ & 5.0 & 5.1 & 5.3 & 5.5 & 5.7 \\
\hline Premenopausal women & $5.29(0.52)$ & 4.9 & 5.1 & 5.3 & 5.4 & 5.6 \\
\hline Postmenopausalwomen & $5.51(0.41)$ & 5.1 & 5.3 & 5.5 & 5.6 & 5.9 \\
\hline \multicolumn{7}{|l|}{$\mathrm{HbA}_{1 \mathrm{c}}(\mathrm{mmol} / \mathrm{mol})$} \\
\hline Men & $37.0(10.0)$ & 31 & 32 & 34 & 38 & 45 \\
\hline Women & $35.3(5.3)$ & 31 & 32 & 34 & 37 & 39 \\
\hline Premenopausal women & $34.3(5.6)$ & 30 & 32 & 34 & 36 & 38 \\
\hline Postmenopausal women & $36.7(4.5)$ & 32 & 34 & 37 & 38 & 41 \\
\hline \multicolumn{7}{|c|}{ Fasting serum insulin $(\mathrm{pmol} / \mathrm{l})$} \\
\hline Men & $37.1(35.5)$ & 12.0 & 18.6 & 28.2 & 43.8 & 64.2 \\
\hline Women & $34.7(50.0)$ & 18.0 & 18.0 & 25.8 & 41.4 & 58.8 \\
\hline Premenopausal women & $33.2(47.0)$ & 10.8 & 17.4 & 25.2 & 40.2 & 58.2 \\
\hline Postmenopausal women & $37.0(54.2)$ & 12.6 & 19.8 & 27.6 & 42.6 & 59.4 \\
\hline
\end{tabular}


a

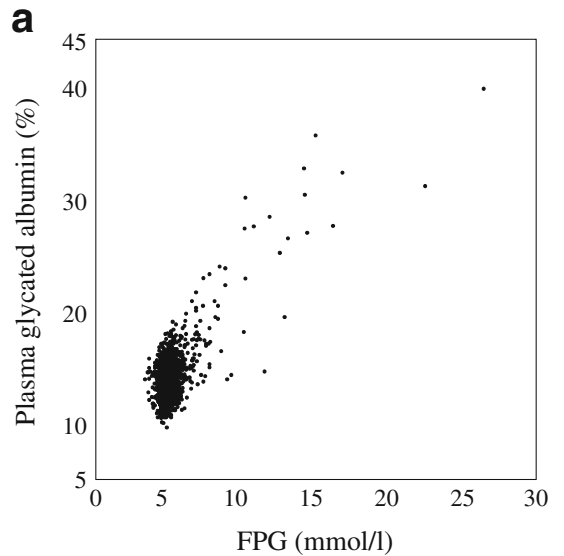

b

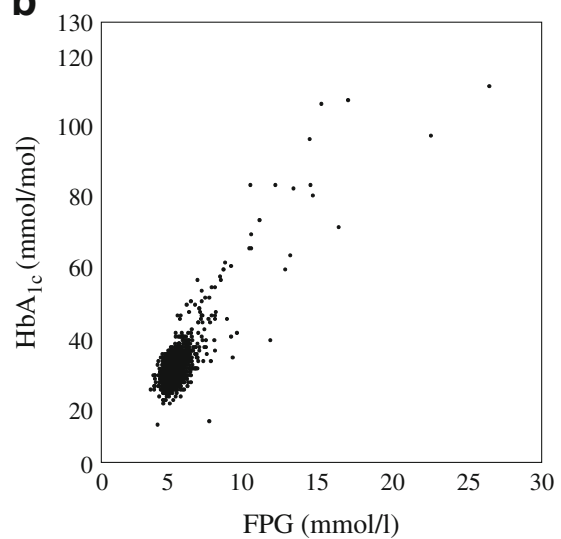

C

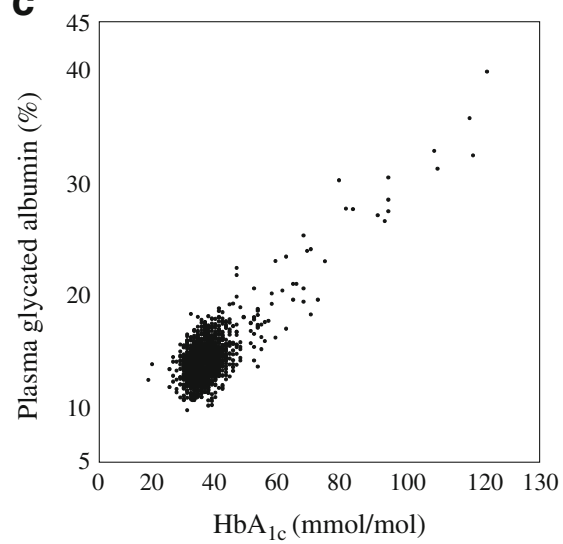

Fig. 1 (a) Correlations between plasma glycated albumin and FPG; (b) correlations between $\mathrm{HbA}_{1 \mathrm{c}}$ and FPG; (c) correlations between plasma glycated albumin and $\mathrm{HbA}_{1 \mathrm{c}}$. To convert values for $\mathrm{HbA}_{1 \mathrm{c}}$ in $\mathrm{mmol} / \mathrm{mol}$ into \%, divide by 10.929 and add 2.15

albumin that best predicted diabetes was $15.5 \%$. The area under the ROC curve was 0.910 , with a sensitivity of $83.3 \%$ and a specificity of $83.3 \%$ (Fig. 3 ).

\section{Discussion}

Glycated albumin is a new measure of glycaemia based on the amount of glucose in serum or plasma attached to albumin, rather than to erythrocyte haemoglobin. The assay is well standardised, and has been automated for high throughput analysis. It has advantages over $\mathrm{HbA}_{1 \mathrm{c}}$ in that it provides a marker of short-term glucose control (23 weeks), rather than 2-3 months [10-17]. In the normal population study presented here, glycated albumin levels did not differ by sex. In contrast, $\mathrm{HbA}_{1 \mathrm{c}}$ levels were significantly higher in men than in women. Significant

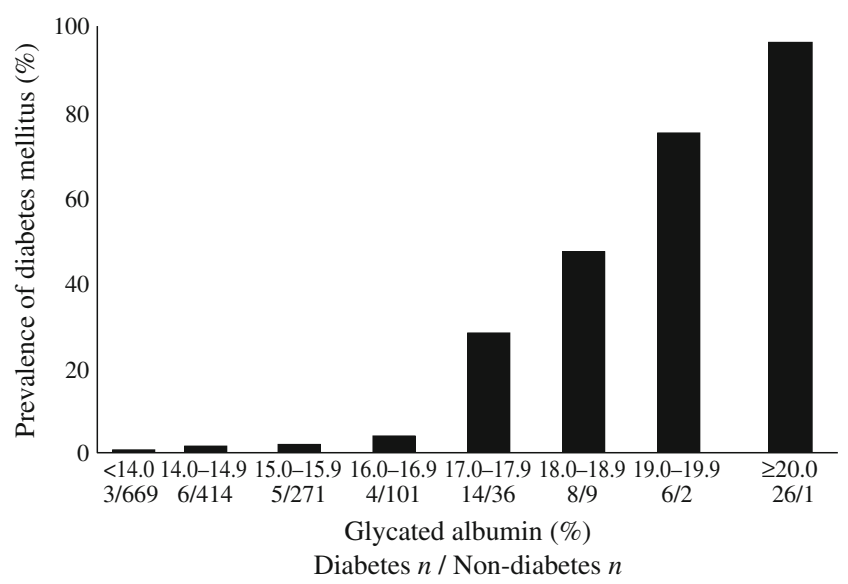

Fig. 2 The prevalence of newly diagnosed diabetes by plsma glycated albumin range. For participants with no history of treatment for diabetes; if FPG was $\geq 7.0 \mathrm{mmol} / 1$, and/or $\mathrm{HbA}_{1 \mathrm{c}}$ was $\geq 6.5 \%$ $(48 \mathrm{mmol} / \mathrm{mol})$, newly acquired diabetes was diagnosed differences between the sexes in BMI, WHR, FPG, $\mathrm{HbA}_{1 \mathrm{c}}$, HDL-cholesterol and triacylglycerol were found in our

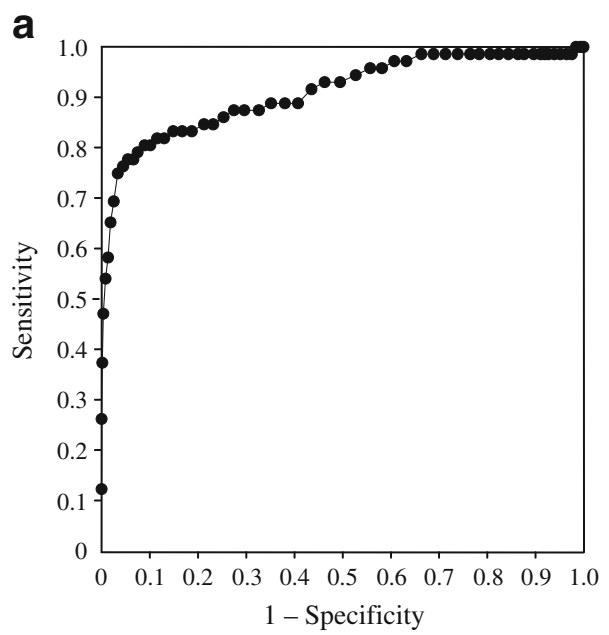

b

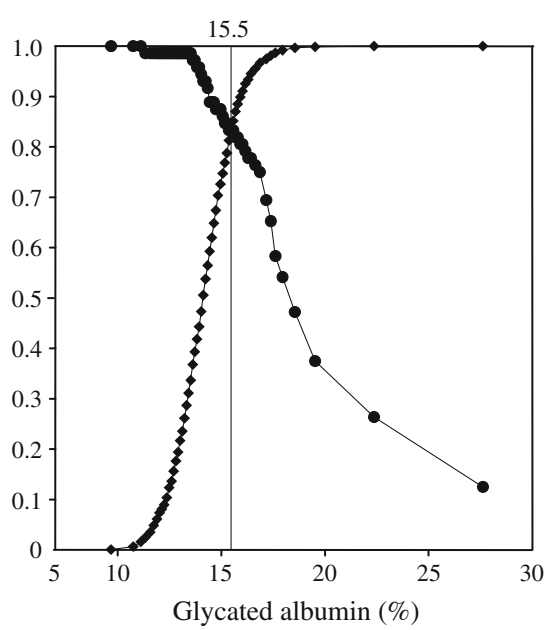

Fig. 3 ROC analysis of plasma glycated albumin cut-off level for detecting newly diagnosed type 2 diabetes. In a, $\mathrm{AUC}=0.910$. In b, circles indicate sensitivity; diamonds indicate specificity 
population, suggesting a higher degree of insulin resistance in the men than in the women. However, there were no significant differences between the sexes in insulin, HOMA-IR or glycated albumin. Therefore, insulin resistance did not differ between the sexes. Thus, for glycated albumin one does not have to take sex differences into account. In fact, the Atherosclerosis Risk in Communities (ARIC) study showed significant differences between the sexes in $\mathrm{HbA}_{1 \mathrm{c}}$ and FPG, but no such significant difference in glycated albumin (men $13.5 \%$ vs. women 13.6\%) [23], consistent with our data.

Both $\mathrm{HbA}_{1 \mathrm{c}}$ and glycated albumin levels have been recognised as markers for mean plasma glucose concentration. A highly positive correlation between $\mathrm{HbA}_{1 \mathrm{c}}$ and glycated albumin levels was observed in this study $(r=0.766)$. This correlation coefficient was somewhat higher than that in previous studies: a case-control study and a study in which all participants were diabetic, where the correlations were approximately $0.70[11,13]$.

Both glycated albumin and $\mathrm{HbA}_{1 \mathrm{c}}$ levels increased significantly with age, as expected. Consistent with these data, both glycated albumin and $\mathrm{HbA}_{1 \mathrm{c}}$ levels were significantly higher in postmenopausal women than in premenopausal women. In the studies presented here, no significant differences were found between the glycated albumin levels in participants with $\mathrm{BMI} \geq 25 \mathrm{~kg} / \mathrm{m}^{2}$ and those with BMI $<25 \mathrm{~kg} / \mathrm{m}^{2}$, while the $\mathrm{HbA}_{1 \mathrm{c}}$ and FPG levels were significantly higher in participants with BMI $\geq 25 \mathrm{~kg} / \mathrm{m}^{2}$ than in those with BMI $<25 \mathrm{~kg} / \mathrm{m}^{2}$. On the other hand, Koga et al. [24] reported that glycated albumin levels are negatively influenced by BMI in Japanese diabetic patients. The present study was conducted with Japanese residents without excluding individuals with high BMI, and no effect of BMI was found. Further study will be required in order to determine the effect of BMI when screening for diabetes using glycated albumin.

In the present study, most participants were free of diabetes, and thus their plasma glucose concentration was supposed to be normal. It is well known that plasma glucose concentration fluctuates widely in patients with diabetes or impaired glucose tolerance. A study using selfmonitoring of blood glucose showed that glycated albumin might be a better marker than $\mathrm{HbA}_{1 \mathrm{c}}$ for evaluating glycolic fluctuations [15]. Another study using continuous glucose monitoring also demonstrated that glycated albumin reflected not only short-term mean plasma glucose concentrations, but also glucose fluctuations [16]. These findings may account for the higher correlation coefficient between $\mathrm{HbA}_{1 \mathrm{c}}$ and glycated albumin found in this study compared with previous studies.

Previous studies have shown a significant positive correlation between $\mathrm{HbA}_{1 \mathrm{c}}$ and glycated albumin levels, and the ratio of glycated albumin to $\mathrm{HbA}_{1 \mathrm{c}}$ was reported to be around 3 in patients with diabetes [25]. In the present study the ratio of glycated albumin:HbA 1 c (NGSP) was 2.68 , which was lower than previously reported [25]. These differences in the ratio may be due to population differences, since the prior studies included patients with previously diagnosed diabetes.

Participants with high glycated albumin levels were more likely than others to have diabetes, as expected. A ROC analysis showed that a glycated albumin level of $15.5 \%$ was best for discriminating patients with diabetes from those without diabetes, with a sensitivity of $83.3 \%$ and a specificity of $83.3 \%$. The area under the ROC curve was 0.91 . These data supported our hypothesis that glycated albumin is a reasonable marker for the screening of diabetes in a medical evaluation.

In this study, a glycated albumin level of $15.5 \%$ corresponded to an FPG of $6.0 \mathrm{mmol} / \mathrm{l}$, and therefore this value serves as an excellent cut-off point for detecting diabetes risk. Our criteria for diabetes in this study were $\mathrm{HbA}_{1 \mathrm{c}} \geq 6.5 \%$ (48 mmol $\left./ \mathrm{mol}\right)$ or $\mathrm{FPG} \geq 7.0 \mathrm{mmol} / \mathrm{l}$. The glycated albumin level that the ROC analysis provided for the best cut-off line for finding diabetes was lower than the level directly estimated from an $\mathrm{HbA}_{1 \mathrm{c}}$ level of $6.5 \%$ (48 mmol $/ \mathrm{mol}$ ) or an FPG of $7.0 \mathrm{mmol} / \mathrm{l}$. This may mean that only one of either $\mathrm{HbA}_{1 \mathrm{c}}$ or FPG reaches the threshold for diagnosing patients with diabetes at an early stage, and that glycated albumin can therefore be useful for detecting patients with diabetes at an earlier stage than is currently possible. Our FPG and $\mathrm{HbA}_{1 \mathrm{c}}$ levels corresponded to a glycated albumin level of $15.5 \%$, and these values were similar to the criteria for the detection of impaired glucose tolerance recommended by the ADA and WHO $[8,9]$. Therefore it would be reasonable to use the cut-off level of glycated albumin for the early detection of glucose intolerance.

Macrovascular diseases are associated with glycaemic fluctuations [3-5] and, as mentioned above, glycated albumin reflects the mean and the fluctuations of plasma glucose concentration. Thus glycated albumin may be an excellent marker for diabetic complications [16], especially for macrovascular disease including cardiovascular diseases. Because our study was cross-sectional, we do not have any direct evidence for the usefulness of glycated albumin for evaluating the risk for diabetic complications, a limitation of this study. A prospective study is required to provide direct evidence for the association between glycated albumin and diabetic complications. However, from the results of the ARIC study, glycated albumin and fructosamine have positive trends in association with microvascular conditions (chronic kidney disease, albuminuria and retinopathy) similar to $\mathrm{HbA}_{1 \mathrm{c}}$, suggesting that these two serum markers of glycaemia may be useful in settings where whole blood is not available [26]. Another 
limitation of this study was that we did not perform OGTTs for our study participants. However, we have begun an investigation of the relationship between glycated albumin and OGTT in the same population to clarify this issue.

Recently, the ARIC study confirmed that $\mathrm{HbA}_{1 \mathrm{c}}$ levels are higher in black individuals than white individuals, even in analyses stratified by diabetes status, and, after adjustment for traditional factors and FPG, that markers of serum protein glycation such as glycated albumin and fructosamine are also higher in black than in white individuals [27]. The present study was conducted only in a general population in Japan. Further studies should be carried out in other ethnic groups.

According to the report by Freedman et al. [28], $\mathrm{HbA}_{1 \mathrm{c}}$ was inversely associated with the GFR in all 254 nephropathy cases, while glycated albumin did not vary significantly based on GFR. Our study excluded cases with nephropathy with an estimated GFR of $\leq 60 \mathrm{ml} \mathrm{min}{ }^{-1} 1.73 \mathrm{~m}^{-2}$ or the presence of macro-albuminuria. In fact, we had no participants with serum albumin concentration $<35 \mathrm{~g} / \mathrm{l}$, which could affect plasma glycated albumin level. Therefore, micro-albuminuria probably does not affect our data for glycated albumin.

The JDS reported that glycated albumin reference intervals were determined to be from $12.3 \%$ to $16.9 \%$ in 2006 (Report of the Committee on Standardization of Laboratory Testing Related to Diabetes Mellitus of the Japan Society) [29]. These data corresponded well to our data, which showed that the reference intervals were from $12.2 \%$ to $16.5 \%$ when using the 10 th and 90 th percentile values of glycated albumin for both men and women (Table 3). However, there are as yet no external quality assessment programmes or international standards for glycated albumin. There is only one manufacturer of the enzymatic method for glycated albumin, and this manufacturer provides standards and external quality assessment materials. The JSCC has reported its recommended method for glycated albumin measurement from serum [30]. International standardisation for glycated albumin is clearly required, if this assay is to become widely used.

In conclusion, there is merit to further investigating the potential for glycated albumin to be used as an alternative measure of dysglycaemia for future research and clinical practice. Our data indicate that glycated albumin can discriminate patients with diabetes from normal individuals. Glycated albumin can be measured from serum or plasma at the same time as blood glucose, while a separate sample of whole blood is required for $\mathrm{HbA}_{1 \mathrm{c}}$. Therefore, glycated albumin may be an optimal tool for diabetes screening, and can be recommended as part of a routine examination to determine if an individual has diabetes. This cross-sectional study was a part of KOPS [18], a prospective, epidemiological, Japanese population study that includes data on intima-media thickness measured by ultrasound of the carotid artery, started in 2004, in which over 15,000 individuals have been examined for the purpose of preventing lifestyle-related diseases. In the future, prospective studies will need to be carried out in order to investigate whether glycated albumin is superior to $\mathrm{HbA}_{1 \mathrm{c}}$ in predicting diabetic complications, including cardiovascular disease. At the present time, we would recommend that glycated albumin $>15.5 \%$ is optimal for predicting the presence of early-phase diabetes in the general population.

Acknowledgements This study was supported in part by the Japan Multi-institutional Collaborative Cohort Study (J-MICC Study) and by a Grant-in-Aid for Comprehensive Research of the 21st Century COE Program from the Ministry of Education, Culture, Sports Science and Technology of Japan. We are grateful to Y Sawayama, M Murata, M Kainuma, K Okada, H Taniai, K Toyoda, E Ogawa, H Ohnishi, H Mukae, M Unno, K Eiraku, T Ihara and T Hayashi of our department for helping with the present study.

Contribution statement The conception and design of the study was carried out by NF, TK, MA, EJS and JH. The measurements were carried out by NF, TK, MA and OS. The data were analysed by NF, TK and MA, and interpreted by all co-authors. All authors contributed to the drafting of the paper and its revision, and are responsible for the intellectual content and the final approval of the version to be published.

Duality of interest MA was supported by a research fellowship from Denka-Seiken Co., Tokyo, Japan, and SO was supported by a research fellowship from Kyowa Medex, Tokyo, Japan. EJS was supported by grants from the National Institutes of Health and the US Department of Agriculture. TK is an employee of the Asahi Kasei Pharma Co., Tokyo, Japan, and this company also donated the glycated albumin assay kits that were used in this study. The authors declare that there is no duality of interest associated with this manuscript.

\section{References}

1. Genuth SM (1995) The case for blood glucose control. Adv Intern Med 40:573-623

2. The Diabetes Control and Complications Trial Research Group (1995) The relationship of glycemic exposure $\left(\mathrm{HbA}_{1 \mathrm{c}}\right)$ to the risk of development and progression of retinopathy in the Diabetes Control and Complications Trial. Diabetes 44:968-983

3. DECODE Study Group (1999) Glucose tolerance and mortality: comparison of WHO and American Diabetes Association diagnostic criteria. The DECODE study group. European Diabetes Epidemiology Group. Diabetes Epidemiology: collaborative analysis of diagnostic criteria in Europe. Lancet 354:617-621.

4. Tominaga $\mathrm{M}$, Eguchi $\mathrm{H}$, Manaka $\mathrm{H}$, Igarashi $\mathrm{K}$, Kato $\mathrm{T}$, Sekikawa A (1999) Impaired glucose tolerance is a risk factor for cardiovascular disease, but not impaired fasting glucose. The Funagata Diabetes Study. Diabetes Care 22:920-924

5. Chiasson JL, Josse RG, Gomis R et al (2003) Acarbose treatment and the risk of cardiovascular disease and hypertension in patients with impaired glucose tolerance: the STOP-NIDDM trial. JAMA 290:486-494

6. UK Prospective Diabetes Study (UKPDS) Group (1998) Intensive blood-glucose control with sulphonylureas or insulin compared 
with conventional treatment and risk of complications in patients with type 2 diabetes (UKPDS 33). Lancet 352:837-853

7. Ohkubo Y, Kishikawa H, Araki E et al (1995) Intensive insulin therapy prevents the progression of diabetic microvascular complications in Japanese patients with non-insulin-dependent diabetes mellitus: a randomized prospective 6-year study. Diabetes Res Clin Pract 28:103-117

8. The International Expert Committee (2009) International committee report on the role of the A1c assay in the diagnosis of diabetes. ADA Workgroup report. Diabetes Care 32:1328-1334

9. WHO (2011) Use of glycated haemoglobin $\left(\mathrm{HbA}_{1 \mathrm{c}}\right)$ in the diagnosis of diabetes mellitus: abbreviated report of a WHO consultation. www.who.int/cardiovascular_diseases/report$\mathrm{HbA}_{1 \mathrm{c} \_} 2011$ _edited.pdf. Accessed 20 January 2011

10. Guthrow CE, Morris MA, Day JF, Thorpe SR, Baynes JW (1979) Enhanced nonenzymatic glucosylation of human serum albumin in diabetes mellitus. Proc Natl Acad Sci USA 76:4258-4261

11. Takahashi S, Uchino H, Shimizu T et al (2007) Comparison of glycated albumin (GA) and glycated hemoglobin $\left(\mathrm{HbA}_{1 \mathrm{c}}\right)$ in type 2 diabetic patients: usefulness of GA for evaluation of short-term changes in glycemic control. Endocr J 54:139-144

12. Tsai LY, Tsai SM, Lin MN, Liu SF (2001) Effect of hemoglobin variants $(\mathrm{Hb} \mathrm{J}, \mathrm{Hb} \mathrm{G}$, and $\mathrm{Hb} \mathrm{E})$ on $\mathrm{HbA}_{1 \mathrm{c}}$ values as measured by cation-exchange HPLC (Diamat). Clin Chem 47:756-758

13. Ai M, Otokozawa S, Schaefer EJ et al (2009) Glycated albumin and direct low density lipoprotein cholesterol levels in type 2 diabetes mellitus. Clin Chim Acta 406:71-74

14. Kouzuma T, Usami T, Yamakoshi M, Takahashi M, Imamura S (2002) An enzymatic method for the measurement of glycated albumin in biological samples. Clin Chim Acta 324:61-71

15. Yoshiuchi K, Matsuhisa M, Katakami N et al (2008) Glycated albumin is a better indicator for glucose excursion than glycated hemoglobin in type 1 and type 2 diabetes. Endocr J 55:503-507

16. Suwa T, Ohta A, Matsui T et al (2010) Relationship between clinical markers of glycemia and glucose excursion evaluated by continuous glucose monitoring (CGM). Endocr J 57:135-140

17. $\mathrm{Lu} \mathrm{L}, \mathrm{Pu} \mathrm{LJ}, \mathrm{Xu} \mathrm{XW}$ et al (2007) Association of serum levels of glycated albumin, C-reactive protein and tumor necrosis factor-alpha with the severity of coronary artery disease and renal impairment in patients with type 2 diabetes mellitus. Clin Biochem 40:810-816

18. Ohnishi H, Sawayama Y, Furusyo N, Maeda S, Tokunaga S, Hayashi J (2010) Risk factors for and the prevalence of peripheral arterial disease and its relationship to carotid atherosclerosis: the Kyushu and Okinawa Population Study (KOPS). J Atheroscler Thromb 30:751-758
19. Koga M, Murai J, Saito H, Otsuki M, Kasayama S (2011) Evaluation of glycated albumin/ $/ \mathrm{HbA}_{1 \mathrm{c}}$ ratio by stage of diabetic nephropathy. Diabetol Int. doi:10.1007/s13340-011-0033-z

20. Matthews DR, Hosker JP, Rudenski AS, Naylor BA, Treacher DF, Turner RC (1985) Homeostasis model assessment: insulin resistance and beta-cell function from fasting plasma glucose and insulin concentrations in man. Diabetologia 28:412-419

21. Geistanger A, Arends S, Berding C et al (2008) Statistical methods for monitoring the relationship between the IFCC reference measurement procedure for hemoglobin A1c and the designated comparison methods in the United States, Japan, and Sweden. Clin Chem 54:1379-1385

22. Nathan DM, Steffes MW, Sun W, Rynders GP, Lachin JM (2011) Determining stability of stored samples retrospectively: the validation of glycated albumin. Clin Chem 57:286-290

23. Schaefer EJ, Audelin MC, McNamara JR et al (2001) Comparison of fasting and postprandial plasma lipoproteins in subjects with and without coronary heart disease. Am J Cardiol 88:1129-1133

24. Koga M, Matsumoto S, Saito H, Kasayama S (2006) Body mass index negatively influences glycated albumin, but not glycated hemoglobin, in diabetic patients. Endocr J 53:387-391

25. Tahara Y (2009) Analysis of the method for conversion between levels of $\mathrm{HbA}_{1 \mathrm{c}}$ and glycated albumin by linear regression analysis using a measurement error model. Diabetes Res Clin Pract 84:224-229

26. Selvin E, Francis LM, Ballantyne CM et al (2011) Nontraditional markers of glycemia: associations with microvascular conditions. Diabetes Care 34:960-967

27. Selvin E, Steffes MW, Ballantyne CM, Hoogeveen RC, Coresh J, Brancati FL (2011) Racial differences in glycemic markers: a cross-sectional analysis of community-based data. Ann Intern Med 154:303-309

28. Freedman BI, Shihabi ZK, Andries L et al (2010) Relationship between assays of glycemia in diabetic subjects with advanced chronic kidney disease. Am J Nephrol 31:375-379

29. Tominaga M, Makino H, Yoshino G et al (2006) Report of the committee on standardization of laboratory testing related to diabetes mellitus of Japan Diabetes Society: determination of reference intervals of hemoglobin A1c (IFCC) and glycoalbumin in the Japanese population. J Japan Diab Soc 49:825-833

30. Committee on Diabetes Mellitus Indices, Japan Society of Clinical Chemistry, Takei I et al (2008) JSCC recommended method for glycated albumin measurement in serum. Jpn J Clin Chem $37: 178-191$ 